\title{
MULHERES, INVESTIGAÇÃO DE PATERNIDADE E JUSTIÇA: COTIDIANO E PROVAS (BELÉM, 1920-1940)
}

\author{
WOMEN, PATERNITY INVESTIGATION AND JUSTICE: EVERYDAY \\ AND EVIDENCE (BELÉM, 1920-1940)
}

DOI: http//dx.doi.org/10.15448/2178-3748.2017.1.26677

Ipojucan Dias Campos

Professor da Faculdade de História da Universidade Federal do Pará (UFPA/IFCH) e docente permanente do Programa de Pós-Graduação da em Ciências da Religião da Universidade do

Estado do Pará (UEPA)

ipojucancampos@gmail.com

\begin{abstract}
RESUMO: $O$ artigo possui como proposta de análise perceber como algumas mulheres e filhos adultos das décadas iniciais do século XX, na cidade de Belém, se articularam tanto no cotidiano quanto no bojo do judiciário para provarem paternidade; assim as interpretações giraram em torno de tramas e lutas de mulheres que constituíram famílias ditas à época "espúrias", às margens do ato solene. Em conformidade, para estes encaminhamentos tomou-se como argumento a concepção de que o tempo de vida sob um mesmo teto sempre se demonstrou princípio indispensável aos que impetravam, aos impetrados, às testemunhas e aos juízes das demandas, porque era em seu interior (no do tempo de convivência) que se buscavam comprovar contatos íntimos e consequentes nascimentos que por razões várias (de o pai ser casado com outra mulher, por exemplo) os impúberes não foram registrados. Nesta seara, é de bom alvitre considerar que as(os) solicitantes em "nada" se sustentavam no desejo de possuir o sobrenome do pretendido genitor, mas sim no de resolver necessidades materiais, as quais poderiam ser "contornadas" por meio de herança e pensão alimentícia.
\end{abstract}

PALAVRAS-CHAVE: Paternidade, família, bens.

ABSTRACT: The article proposes to analyze how some women and adult children of the early decades of the twentieth century, in the city of Belém, articulated both in daily life and in the bulge of the judiciary to prove paternity; the interpretations revolved around the plots and struggles of women who constituted families called "spurious" times, on the margins of the solemn act. Accordingly, for these referrals, the idea was that the life time under one roof always proved to be a necessary principle for those who impelled, for the defendants, for the witnesses and for the judges of the demands, because it was within them (In the time of coexistence) that sought to prove intimate contacts and consequent births that at that time, for various reasons (for the father to be married to another woman, for example) the unpublished were not registered. In this section, it is good practice to consider that the applicants in "nothing" were based on the desire to have the surname of the intended parent, but on the need to solve material needs, which would be "bypassed" through inheritance and pension food.

KEYWORDS: Paternity, family, goods. 


\section{Introdução}

Pais não matrimoniados, descendência não reconhecida e contendas sob o mesmo teto, foram algumas combinações - na cidade de Belém entre 1920 e 1940, que sustentaram a abertura de Autos de Investigação de Paternidade. Quando o casal "amásio" perdia padrões de convivência e os rebentos eram irreconhecidos, como as mulheres comprovavam paternidade? De que modo a experiência se articulava com as determinações do direito para se verificar a paternidade de um descendente ilegítimo? ${ }^{1}$ Estes são alguns campos que o presente artigo procura dar conta. Então, enfatize-se que existia apenas aparente distinção entre os códigos ditos legais [os do direito] e os da esfera do cotidiano; aliás o conjunto de leis do dia a dia se fazia presente e formava cadeias constantes com as dimensões das teias jurídicas. Nestes domínios Michael Foucault, ajuda. Disse o autor que a ordem jurídica em suas práticas sociais engendra espaços de poder e saber, mas que estes não são unicamente articulações que surgem em si, isto é, os conceitos jurídicos, juntamente com suas técnicas são forjados no transcorrer do ato de julgar, assim sendo o direito não disponibiliza de único padrão de julgamento. (FOUCAULT, 2003).

Se por um lado existiam táticas desejadas bem definidas e que se encontravam na legislação do início do século XX, por outro havia as tácitas [as do cotidiano] que funcionavam de modo competente quando acionadas. Para o Código Civil Brasileiro de 1916, os caminhos legais - às mulheres - para se obter sucesso em uma ação de paternidade concentravam-se em: estar a mulher concubinada com o pretendido pai, a concepção do filho coincidisse com o rapto da mãe e que existissem a respeito escritos daquele a quem se responsabilizava a paternidade. (Artigo 363, Código Civil, 1917). Tratava-se de exigências bastante complexas e as únicas aparentemente "possíveis" a quem desejasse comprovar filiação paterna.

Mulheres, filhos e advogados organizavam-se diante das exigências, necessidades e desejos do judiciário, mas também se deve lembrar que neste o cotidiano fazia-se importante, porque dele surgiam possibilidades e estratégias que podiam convergir aos anseios jurídicos. Com efeito, os argumentos contidos neste artigo concentram-se na

\footnotetext{
${ }^{1}$ Segundo Clóvis Bevilaqua os filhos ilegítimos, a legislação do início do século XX, os classificou em duas categorias, quais sejam: naturais e espúrios. Os primeiros são aqueles em que os pais poderiam se casar, todavia por razões várias não celebraram o ato solene. Quanto aos segundos, foram subdivididos em incestuosos e adulterinos. Os incestuosos classificaram-se como os gerados entre parentes até o grau em que a lei proíbe o casamento. Já os adulterinos eram os que procederam de relacionamento entre casados ou quando um ou outro era matrimoniado. Veja-se a este respeito: BEVILAQUA, Clovis. Código Civil dos Estados Unidos do Brasil. Vol. II. São Paulo: Livraria Francisco Alves, 1952, p. 294.
} 
concepção de que o tempo de vida a dois mostrava-se indispensável para que os profissionais da lei (juízes) tomassem decisões acerca dos elos maritais, uma vez que dele (do tempo sob um mesmo lar) provinham narrativas de determinado momento da vida amorosa daqueles que agora se encontravam em litígio.

Desta maneira, para se interpretar tais inquietações, os seguintes documentos jurídicos mostraram-se essenciais: Autos de Investigação de Paternidade e Alimentos, Código Civil Brasileiro de 1916, bem como comentários deste realizado por Clóvis Bevilaqua. Mas também, entre 1920 e 1940,foram compulsadas matérias dos jornais "Folha do Norte" e o católico "A Palavra" as quais contribuíram sobejamente às investidas aqui apresentadas.

A respeito da sua localização, os Autos de Investigação de Paternidade e de Pensão Alimentícia foram pesquisados no Arquivo do Tribunal de Justiça do Estado do Pará, onde "inexistia" forma organizativa que tornasse exequível indicar de maneira exata onde os papéis repousavam: fundo, série, subsérie, por exemplo. ${ }^{2}$ Por seu turno, os periódicos "Folha do Norte" e o católico "A Palavra" encontram-se na Hemeroteca Estadual Arthur Vianna ("A Palavra", também pode ser consultado no Arquivo da Cúria Metropolitana de Belém (ACMB)). O Código Civil Brasileiro e a obra de Clóvis Bevilaqua (Código Civil dos Estados Unidos do Brasil. Vol. II) são livros que constituem acervo particular deste historiador.

\section{Como provar paternidade no início do século XX?}

As intimidades de Izaura Gomes de Lima, 26 anos, paraense, doméstica, casada, porém em 1940 separada do esposo e seu ex-amásio Carlos Flaviano do Nascimento, paraense, solteiro, marítimo, precisaram vir à tona quando o homem deixou de dar assistência financeira à família constituída. (Auto Civil de Investigação de Paternidade, 1940). Vindo o seu marido falecer somente em 1937, a impetrante mantinha-se em estado de casada-adúlteraamásia. Esta convivência dita "espúria" à época era questionada por expressivas forças sociais belenenses, a este respeito "A Palavra" com o título "Divórcio", condenava posturas como as tomadas por dona Izaura. A Igreja por meio deste veículo afirmava: "Enquanto vive o marido, será chamada (a mulher) adultera, se communicar com outro homem; se porém morrer o seu marido, fica livre e não será adultera, ligando-se com outro". (A Palavra.Belém, 09 de setembro de 1923, p. 01). Utilizavam-se São Paulo em Epístola aos Romanos para condenar práticas sexuais fora do matrimônio, pois que mesmo uma mulher separada do esposo [ela] cometeria adultério se contratasse relações carnais com outro, porque a “mulher casada está

\footnotetext{
${ }^{2}$ É de bom alvitre expor que, hoje, estes documentos encontram-se sob a guarda do Centro de Memória da Amazônia (CMA), espaço administrado pela Universidade Federal do Pará (UFPA).
} 
ligada por lei ao marido enquanto ele vivo; se o marido vier a falecer, ficará livre da lei do marido". (Artigo 363, Código Civil, 1917). Deve-se enfatizar que o matrimônio à Igreja se caracterizava como sacramento e era indissolúvel, o qual findava com a morte de um dos cônjuges. Nesta esteira, para Ipojucan Dias Campos, a legislação civil que vigia no início do século XX muito se aproximava ou era parte da doutrina da Igreja; em outros termos, a mulher e o homem (os cônjuges) separados formalmente por meio de desquite ou de maneira informal (sem a presença da justiça) cometeriam adultério se mantivessem qualquer intimidade com outro(a), isto acontecia em virtude de o desquite "apenas" estabelecer a separação perpétua de corpos e bens, não dissolvendo os laços matrimoniais, pois as bodas eram indissolúveis não apenas para a Igreja, mas também à lei. (CAMPOS, 2010, p. 179-201).

Segundo Paulo Sá, a Igreja Católica lutou contra toda e qualquer possibilidade de introdução do divórcio na sociedade brasileira, visto que tal instituto representava a instabilidade dos elos familiares, quiçá o seu fim. (SÁ, 1946). Para este estudo também dinamizar interpretações com Sueann Caulfield é coerente. A historiadora ao debater moralidade, honra e nação considerou que a manutenção do casamento sempre foi desejo da Igreja e do Estado, porquanto compreendiam que o conúbio proporcionava estabilidade à família, segurança econômico-social e mesmo de sobrevivência. (CAULFIELD, 2000).

Então, a Lei Civil e a Epístola atrás citadas explicam o porquê Carlos e Izaura fizeram percursos contrários ao que se queria impor como homogêneo e higiênico. O filho Raymundo [no auto não foi publicizado o seu sobrenome] pela lei, em tempo algum poderia ser legitimado, pois a prole adulterina jamais seria reconhecida, mas as mulheres - quando desses casos - era comum por meio de processo conseguir pensão alimentícia, ou seja, se impossível era reconhecê-los, nunca perdiam o direito à pensão. Os filhos surgidos de um desquitado ou casado com um solteiro ou entre aqueles seriam ilegítimos em qualquer tempo: quando casado por razões óbvias e na condição de desquitado porque esta ação dissolvia "somente" a sociedade conjugal e não os vínculos formados pelo ato solene uma vez que inexistia o divórcio perpétuo no Brasil, enfatize-se. Destarte, obrigavam os cônjuges aos mesmos deveres de fidelidades ditos indispensáveis à vigência da vida conjugal como se juntos estivessem.

Porém volte-se à relação em questão. Dela nasceu uma criança, em 13 de junho de 1933, e nenhuma responsabilidade foi assumida pelo pretendido genitor, sendo que em 1940, sete anos depois do seu nascimento, dona Izaura impetrou processo de investigação de paternidade cumulado com o de provisão e a rigor o objetivo central da mulher era o de provar ser Carlos o pai da criança para que a ação de alimentos se tornasse legítima. 
Conforme Jeni Vaitsman, aqueles que defendiam a família conjugal deveriam tomar precauções e reticências, pois o momento histórico exigia, porquanto valores que legitimavam e regulamentavam normas e papéis eram questionados, isto é, os anseios que fundamentavam as concepções da linhagem vista como [pela Igreja e Estado] ideal e oficial colocavam-se frequentemente em xeque. (VAITSMAN, 1994).

Neste caso, quais estratégias as mulheres poderiam estabelecer para que se tivesse a possibilidade mínima de sucesso nos corredores do judiciário? As que enfrentassem esta natureza de processo teriam de articular a cotidianidade com a legislação. A autora (Izaura), juntamente com o Assistente Judiciário Vicente Portugal Junior, estabeleceram a tática de percorrer com firmeza e afinco, em primeiro lugar, o dia a dia do casal para depois entrelaçálo com a jurisprudência da época. Este ardil explica-se em virtude de as provas conseguidas "não serem" consistentes às exigências do direito; em outras palavras havia os seguintes indícios de culpa contra o réu: promessas constantes de casamento; registro de nascimento de Raymundo e o ano em que o amasiamento teve início, 1932. Não haver "provas cabais": cartas ou qualquer outro papel escrito por Carlos Flaviano em que se confirmasse a paternidade. As possíveis promessas de enlace poderiam ser facilmente refutadas, porque a mulher, durante boa parte da vida marital, manteve-se casada com outro; sobre o registro de nascimento de Raymundo, a genitora foi a declarante e os avós paternos não apareciam no documento. Provar o início do amasiamento e consequentes atos carnais apresentavam-se importantes estratégias naquele momento, visto que o inciso II, do artigo 363 do Código Civil afirmava: "Se a concepção do filho reclamante coincidiu com o rapto da mãe pelo suposto pae, ou suas relações sexuaes com ella" há a prova de culpabilização do impetrado. (Código Civil, 1917).

Como seria exequível construir discursos suficientemente fortes para convencer o poder judiciário acerca da acusação de que Raymundo nasceu quando a impetrante e o réu viviam amasiados? Havia-se de recorrer ao cotidiano. Utilizar o filho de quem se deseja provar paternidade era ferramenta fundamental para esse fim, ou seja, publicizar os predicados sócio-econômicos fazia parte do jogo; aliás, saber localizar-se bem nele era capital às pretensões desejadas. Em depoimento, a mulher afirmava ter procurado o amante para que provesse a criança, porque inexistiam recursos de espécie alguma que viabilizassem tamanha responsabilidade. Diante do anunciado, “o réu não se incomodou com o menor e não auxiliou com cousa alguma e vivendo o menor como vagabundo, solto na rua". (Auto civil de Investigação de Paternidade Cumulado com Prestação de Alimentos, 1940). Recorrentemente as mulheres usavam os filhos nos espaços do judiciário, estratégia que se constituiu em ardil 
para se conseguir veredictos favoráveis. Traçar hábitos, costumes, condições da vida financeira-social, como o estado da casa onde a mulher e os rebentos viviam, significava parte expressiva do jogo de poder à comprovação da paternidade. Também nesta conjuntura é impossível deixar de acentuar as pressões que Carlos recebeu por meio de adjetivos que talvez lhe fossem incomuns como o de pai desnaturado que permitia caísse sobre o "filho" o epíteto de vagabundo. Representava-se o pretendido pai de maneira múltipla e comprometedora: a condição de não provedor estendia-se à de responsável pela formação de vagabundos, fato que o complicava consideravelmente à justiça. Utilizava-se a criança com destreza para localizar Carlos - moralmente - em situação nevrálgica perante o direito e os seus.

Mais e mais argumentos femininos, provas, cotidiano eram fundantes aos caminhos da vitória jurídica. Com este fim, depôs a testemunha Jorge Alves Teixeira, 54 anos, brasileiro, casado, operário, residente na Rua Curuçá, 360, ele procurava ajudar a impetrante dos processos, ao expor que poderia "informar com precisão que a autora teve ha cinco anos mais ou menos um filho com o réu". (Auto Civil de Investigação de Paternidade Cumulado com Prestação de Alimentos Impetrado, 1940). Mesmo que a obrigação de se constituir testemunhas não houvesse no artigo 363 do Código Civil, a sua presença no seio dos autos mostrou-se essencial. O senhor Jorge dizia ser capaz de "informar com precisão" as intimidades do casal porque os contendores eram seus vizinhos. Assim sendo, a proximidade proporcionava momentos múltiplos e diversos onde participar da vida privada dos litigantes não era raro, assim os movimentos, as ações, as palavras, os gestos da vizinhança são campos importantes em um auto de investigação de paternidade e de tal sorte, fazia-se necessário usar o conhecimento que ela detinha sobre os passos uns dos outros, para que este vizindário quando acionado - nos campos da justiça - se transformasse "facilmente" em úteis depoentes.

As palavras de Jorge demonstravam viável intimidade, visto que ele afirmava diante do juiz, Mauricio Cordovil Pinto, "que viu varias vezes o réu agradar o referido menor e ouviu trata-lo de filho". (Auto Civil de Investigação de Paternidade Cumulado com Prestação de Alimentos, 1940). Inexistiam cartas onde o impetrado reconhecesse a paternidade, no entanto construíram-se outras estratégias na tentativa de comprovar o que se queria. A testemunha afirmava ser próxima dos amásios e argumentava, no judiciário, que múltiplas vezes presenciou Carlos oferecendo afagos à criança; nestes domínios tênues, a fabricação de discursos era primordial, tanto que os mesmos se formulavam conforme as conveniências dos que se encontravam em litígio, sendo igualmente de fundamental importância entender que as narrativas se faziam a partir de construções nos espaços da experiência. Como afirmou Nicole Castan em "O público e o particular", aqueles próximos 
geograficamente, os vizinhos, têm o poder de sentir, experimentar, compreender os lugares mais exíguos da família do outro, isto é, caso não se construísse prudência a vizinhança era capaz e sempre se apresentava habilitada a conhecer e a reconhecer em detalhes a vida do outro. (CASTAN, 1991, p. 413-453).

A rigor, cartas, duração do amasiamento conjugado com a época da gravidez bem como as versões das testemunhas, empregavam-se na formulação de táticas desejadas coerentes diante do poder jurídico para se obter veredicto favorável. A mulher conseguir estabelecer boa articulação da vivência amásia significava caminhar incisivamente sobre as possibilidades da comprovação. Via-se a mediação do tempo relacionada diretamente com as tramas sociais, culturais, políticas que norteavam a vida em comum de Carlos e Izaura; em outros termos, os espaços cotidianos possuíam suas próprias lógicas que impossibilitavam cronogramas prévios; entretanto, em outro momento, é demasiadamente óbvio observar que a sucessão dos fatos vividos organizava-se na ânsia da comprovação da paternidade. Esses regulamentos localizavam-se na experiência de vida não apenas dos amásios e do filho, mas também na das testemunhas, do Assistente Judiciário e do juiz. Este provavelmente sincronizava-se com o tempo, porque era preciso estabelecer somas e observações acerca do nascimento de Raymundo com o período do amasiamento. Deve-se reafirmar que esta forma de vida a dois não era recomendada pela Igreja, Estado e por parte da sociedade. Sobre este assunto, Anne Martin-Fugier articulou que a celebração da família exigia “pequenos”, porém importantes campos de preparativos à consumação do casamento ideal, exemplar neste sentido é quando se pensa a caminhada da mulher: adolescência, primeira comunhão, namoro regrado e não longo para em seguida noivar e celebrar matrimônio. (MARTIN-FUGIER, 1999, p. 193-261). O desejado, o afã, o ideal era de os filhos virem depois do ato solene e a vida a dois terminar em virtude da morte de um dos consortes. Fora destas condições, o preconceito agia pois em cadeia sobre as mulheres que resolvessem ter filhos fora do matrimônio bem como às desquitadas, afirmou Carmen da Silva. (SILVA, 1968).

Exemplos importantes neste sentido são as ações de Maria Jacyntha Felix, 32 anos, solteira, serviços domésticos, brasileira contra Raymundo Pereira de Souza, que morreu em acidente ferroviário no Rio de Janeiro, embarcadiço, solteiro.Maria empregou, em 1921, táticas adequadas na investigação de paternidade contra o pai dofinado, Vicente Pereira Leal (seu sogro). Da vida marital dos amásios, houve três filhos:RaymundaFiderina de Souza, nascida em 24 de abril de 1913; Manoel Beda de Souza, nascido em 27 de maio de 1915 e Maria de Lourdes de Souza, nascida em 24 de janeiro de 1920. (Auto Civil de Investigação de Paternidade, 1921). Todavia é preciso ser mais elucidativo: uma mulher (Maria Jacyntha 
Felix) abriu processo de paternidade contra o pai de seu companheiro, Raymundo Pereira de Souza morto no Rio de Janeiro, para provar que três filhos foram concebidos entre eles. As alegações da amásia pautavam-se nas dimensões do social vivido: que teriam tido vida marital por bastante tempo, que a união e os filhos eram vistos como legítimos entre a vizinhança e "pessôas das relações do casal"; que todas as vezes em que o amásio se ausentava de Belém deixava dinheiro suficiente para ela e sua prole na residência onde moravam, sita à Travessa Francisco Monteiro, Bairro de Queluz, “em companhia de uma afilhada e de uma irmã delle”; que sobre a reputação da mulher jamais nenhuma dúvida pairou; que o falecido apresentava os menores como seus verdadeiro filhos. As mulheres que desejassem provar paternidade investiam sempre pelos meandros do cotidiano, porque neles localizavam-se as provas a alcançar veredictos favoráveis. Na cidade de Belém, o tempo da concepção ou da probabilidade dela é marcado por regularidades que não aquelas desejadas [conforme elites, Estado, Igreja Católica], nem tampouco segundo a pretensa norma moral e sim pelas simetrias e regularidades dos envolvidos nas argumentações que se queriam comprovar.

Outro caso que ajuda a entender os significados dos processos de paternidade é o impetrado por Alzira Gonçalves Galeão contra os herdeiros de Demetrio Moreira Pereira Lima. (Auto Civil de Investigação de Paternidade e Petição de Herança, 1940). Cerca de oito anos após a morte do amásio, a ação foi iniciada e rezava que a trajetória da vida marital teve início em 1925 e que do viver sob o mesmo teto houve três filhos: Eduardo, nascido em 21 de fevereiro de 1927; Leonardo, nascido em 10 de novembro de 1928 e Eunice, em 11 de abril de 1930. Neste caso a mulher era portadora de documento escrito, deixado por Demetrio, pois o falecido batizou um dos descendentes, Leonardo. Coerentemente, anexou o papel expedido pela Arquidiocese de Belém aos autos de paternidade cumulada com o de herança. O mundo privado do casal abria-se ao judiciário na mesma velocidade das possibilidades do veredicto favorável, mas outras geografias da vivência facilitavam a presteza da ação: os silêncios sepulcrais dos herdeiros, apontamentos anexados e duas testemunhas, davam o tom de que a paternidade se mostrava indiscutível. A mulher e novamente Vicente Portugal Junior incorporaram aos autos manuscrito expedido pelo Dr. Carlos Silva, - que realizou o parto de Eunice - com teor seguinte:

attesto ter sido medico assistente de D. Alzira Gonçalves Galeão, na Ordem Terceira nesta Capital na occasião de seu parto da creança Eunice, nascida, a termo em 11 de abril de 1930, tendo sido meus serviços profissionaes pagos por Demetrio Moreira Lima. (Auto Civil de Investigação de Paternidade e Petição de Herança, 1940). 
Verifica-se novamente o uso das experiências cotidianas no judiciário. As declarações do médico que fez o parto da filha do casal funcionavam como portadoras de força social, bem como assertivas de confiabilidade. O percurso para a condenação do réu ainda pode ser palmilhado ao se entrecruzar a data do nascimento da criança com a que foi expedida no documento, onde se afirmava que o senhor Demetrio compromissava-se com os custos do parto. No entanto, há a esclarecer que o papel é de 19 de agosto de 1940, enquanto o nascimento ocorreu em 11 de abril de 1930, ou seja, dez anos depois a impetrante solicitou ao médico que escrevesse declaração informando as responsabilidades que o amásio assumia com ela. O período entre o nascimento e o documento também deve ser analisado, pois o judiciário paraense possivelmente o tomou como prova de confiabilidade, uma vez que mesmo tendo passado certo tempo, o profissional confirmou proximidades íntimas entre a mulher e o falecido.

As articulações condenatórias não pararam. Constituíram-se duas testemunhas: Dulce Seixas Duarte, brasileira, solteira, serviços domésticos, que residia a Rua Oliveira Belo, 138, confirmava em juízo que o casal convivia "em companhia um do outro desde o âno de 1925" e complementava afirmando "que até a data do falecimento de Demetrioêles viviam juntos". (Auto Civil de Investigação de Paternidade e Petição de Herança, 1940). Outra testemunha que deu a sua versão dos fatos foi Consuelo de Seixas Duarte, brasileira, solteira, serviços domésticos, residente no mesmo endereço que afirmava ter sido a morte que separou os amásios e que "Demetrio apresentava a todos os conhecidos esses meninos como seus filhos". (Auto Civil de Investigação de Paternidade e Petição de Herança, 1940). Em 22 de dezembro de 1940, o juiz Mauricio Cordovil Pinto proferiu sentença favorável à impetrante. O dia a dia em princípio privado transformava-se em público ao atender às necessidades das pessoas, assim o cotidiano deve também ser visto como espaço multifacetado do privado.

Nesta conjuntura, mesmo pesquisando para outro tempo e espaço, Richard Sennett alerta que o privado se transforma - conforme as conveniências - em lugar público; de tal sorte, pode ser compreendido como um modo de ser em si e também dos membros do ciclo que o formava. (SENNETT, 2002, p. 117-137). Uma investigação de paternidade não pode ser entendida apenas como espaço singular, pois as teias em pauta envolviam mundo mais amplo, no exemplo o das relações de vizinhança ao médico que realizou o parto. As testemunhas eram acordes em afirmar que o casal viveu com os seus três filhos "ate a data do falecimento de Demetrio". Muito embora sem as bênçãos, atendia-se rigorosamente o princípio: até que a morte os separasse, como se casados legalmente fossem. Naturalmente a Igreja Católica nada recomendava tal maneira de viver e a este respeito parafraseando Gérard 
Vincent para as "diversidades culturais" católicas, no início do século XX, o casamento era vislumbrado como obrigação àqueles que desejassem viver em Cristo. (VINCENT, 1995a, p. 393-425).

Três fatos básicos podem explicar, grosso modo, as trajetórias realizadas pelas mulheres desses autos: quando sentiam a prole ameaçada, quando o homem se recusava a reconhecer a filiação e por falecimento do companheiro. Era imperativo ressabiar-se, uma vez que seria desastroso sair da vida a dois bruscamente, sem garantias para si e aos filhos. Em 01 de novembro de 1940, o periódico "Folha do Norte", publicou que o

juizo da $4^{\mathrm{a}}$ vara - o dr. Cordovil Pinto - designou o dia 8 do mez fluente, para a instrucção e julgamento da acção de investigação de paternidade que Alzira Gonçalves Galvão move contra os herdeiros de Demetrio Moreira Pereira Lima. (Folha do Norte. Belém, 01 de novembro de 1940, p. 02).

Ao juiz foi facilitada a sentença favorável à mulher, pois os herdeiros eximiram-se em executar qualquer contestação. Leia-se parte da sentença:

julgo procedente a justificação de fls. 14 e verso, para que produza os seus efeitos legais, e em consequencia, determino a expedição do mandado competente, para o registro dos menores Eduardo, Leopoldo e Eunice, de 13, 12 e 11 anos respectivamente, como filhos naturais reconhecidos do falecido Demetrio Moreira Pereira Lima e Alzira Gonçalves Galeão, de acôrdo com os itens da petição de fls. 2, e conforme permite o Código Civil Brasileiro. (Auto Civil de Investigação de Paternidade e Petição de Herança, 1940).

No estudo em pauta, os argumentos femininos concentravam-se nos interstícios do cotidiano e a este respeito, Maria Odila Leite da Silva Dias argumenta ser imprescindível perceber os sujeitos sociais como agente-condutores de si mesmos. (DIAS, 1992, p. 39-53). Assim sendo, mais um caso dentre diversos que converge ao anterior e que pode reforçar os argumentos que por ora se apresentam é o processo de investigação de paternidade cumulado com o de petição de herança impetrado por Ladi Silva, 40 anos, paraense, solteira, serviços domésticos, patrocinada pela Assistência Judiciária contra os herdeiros de seu ex-amásio José Marques dos Santos, 37 anos, paraense, servente, falecido na Santa Casa de Belém a 11 de outubro de 1940 de Pneumonia. (Auto Civil de Investigação de Paternidade, 1940). A mulher argumentava em juízo que se amasiara com José em 1924 e que da vida marital provieram duas filhas: Joana Santos, 15 anos e Alice Santos, 14 anos. O auto era movido contra o pai do amante, Eugenio Manoel dos Santos, 55 anos, paraense, casado, carpinteiro. A mulher constituiu duas testemunhas, a saber: Daniel AntonioMeninéa, 50 anos, paraense, casado, carpinteiro e Pedro Ferreira Mendes, 44 anos, paraense, casado, comerciante. Os depoentes 
afirmavam reconhecer a vida amásia de Ladi com o falecido, que dos nove anos de união vieram ao mundo duas crianças e Pedro assegurava que o senhor José costumava ir à sua casa comercial em companhia das duas impúberes e que as considerava, publicamente, como suas filhas. Em declaração realizada à justiça Eugenio, pai do falecido, confirmava que reconhecia a vivência amásia do filho com Ladi e que desta união houve duas meninas, suas netas. As declarações das testemunhas bem como as do pai (do falecido amásio) facilitaram juridicamente a sentença favorável proferida, em 28 de dezembro de 1940, por Mauricio Cordovil Pinto.

Nestes e em outros casos, o fator tempo deve ser entendido como indispensável para que juízes tomassem decisões acerca dos elos maritais, uma vez que expressava discursos acontecidos em determinado momento. Por exemplo, o nascimento dos filhos do casal e o início da vida em comum com o presente histórico de Ladi, o qual se concentrava na comprovação da paternidade da prole. O que impressiona nestas tramas são os posicionamentos que se tomavam no espaço da experiência cotidiana, isto é, como se consignavam vínculos de certezas e verdades às testemunhas. Comprovar paternidade significava a busca de si e logicamente do outro no [determinado] tempo em que os fatos aconteceram, porque era preciso determinar um lugardo admissível; saturar os espaços transitados quando da vigência da vida amásia. Traçar um catálogo da vida a dois funcionava sempre como proteção a qualquer ato em contrário, tanto quanto as resistências do pretendido pai em assumir as suas responsabilidades. Neste tipo de ação palmilhavam-se jogos associativos e comparações, pois percorriam-se espaços dos discursos de convencimento os quais enveredavam pelo mosaico das provas. Aos que "esqueciam" das promessas feitas por ocasião do namoro, do amasiamento ou de outro movimento de vida a dois, articular-se com o tempo vivido foi prática constante para se dar base a estes autos.

Eles organizavam-se em movimentos judiciais prenhes de complexidade. A condição de requerente e requerido nem sempre se encerrava apenas entre amásios, porquanto foram críveis diversas combinações: "amásias" representando contra o pai do companheiro por falecimento desse, como foi o caso de Maria Jacyntha Felix contra Vicente Pereira Leal, (Auto Civil de Investigação de Paternidade, 1921); "amásias" contra filhos e filhas legítimos de seus companheiros em virtude de passamento desses, como foi o caso de Antonia Pereira de Lima contra as herdeiras de João Bussons, (Auto Civil de Investigação de Paternidade, 1931); filhos ilegítimos contra os herdeiros legítimos de seus pretendidos pais, como foram os casos de Luiza Ramos do Nascimento contra os herdeiros de Manoel Ramos do Nascimento e Antonio da Silva Borges e outros contra Preciosa Rodrigues Borges, (Auto Civil de 
Investigação de Paternidade, 1931); irmão impetrando processo contra irmãos, em decorrência da morte do pretendido pai, como foram as tramas entre Josias Maia contra Zulmira Catharina Maia do Nascimento. (Auto Civil de Investigação de Paternidade, 1921). Quando se feriam interesses, os ajustes, argumentações e arguições surgiam entre interessados em provar a desejada paternidade irreconhecida em vida do companheiro, quando da morte deste e mesmo durante a vivência sob o mesmo teto.

Diante do exposto, a investigação de paternidade ia além do justo desejo de possuir o nome do pretendido genitor. Esta premissa, aliás, localizava-se em segundo plano. Assim é necessário enfatizar que a figura do pai mostrava-se importante, nem tanto em relação ao nome, mas sobretudo ao seu trabalho, vencimentos e bens. Existiam para as mulheres neste tipo de ação, sentidos de recompensa moral por terem ajudado a construir patrimônio, tolerado embriaguez, suportado ameaças de outras mulheres e as do próprio companheiro. Articular eixos próximos, contudo com resultados bem distintos, é salutar. Michelle Perrot analisou que na vida privada oitocentista a figura do pai com o seu sobrenome mostrava-se importante, porque a partir de leituras de teóricos como Hegel, Proudhon e Kant entendeu que quem realmente dava à luz era o homem, por meio do seu sobrenome. (PERROT, 2001, p. 121-192). Para a cidade de Belém, contudo, tal fato sequer se apresentava como questão, uma vez que às mulheres os autos partiam e indicavam a uma segurança de subsistência, tanto que vários se cumulavam com o de pensão alimentícia, embora também se organizassem diante da divisão de bens, haja vista que diversos processos surgiram em virtude da morte dos companheiros.

Tomando como base os documentos analisados, boa parte dos filhos à época chamados ilegítimos mantinha contatos contemporâneos com o "pai", ou seja, solidariedade, sustento e proteção faziam-se presentes entre o grupo familiar. Geralmente os problemas que envolviam os bens e provisões surgiam quando o suposto progenitor se eximia da proteção dos seus supostos rebentos bem como da amásia. Quando morriam e deixavam as combinações: filhos reconhecidos $x$ ilegítimos, filhos legítimos $x$ ilegítimos e filhos legitimados $x$ ilegítimos, facilmente os primeiros ou seus responsáveis eram submetidos a ações de paternidade diante da justiça.

A existência de algum patrimônio intestado ao tempo do falecimento do possuidor trazia aos herdeiros grandes problemas. Se alguns se digladiavam por poucos dias por ter vencido ou por a outra parte ter desistido da ação, outros permaneciam por meses a fio nos corredores do judiciário. Se alguns lutavam por uma partilha dita mais justa dos móveis e imóveis deixados pelos pretensos genitores, outros buscavam o total dos bens [contra 
supostos filhos ilegítimos], conseguidos durante anos de intenso trabalho dos pais. Muito embora problemas concentrados na partilha se verificassem em alguns autos, o número esmagador de processos tinha como fim a mulher conseguir "tão somente" pensão alimentícia e não necessariamente a divisão de móveis e imóveis. Para esta questão duas explicações são bastante lógicas; primeira, os documentos indicam que $87 \%$ dos impetrados podem ser classificados como homens pobres para o início das primeiras décadas novecentista, quer-se dizer: funcionários do porto, empregados no comércio, carpinteiros, pedreiros, embarcadiços, braçais, serventes, os quais acumularam poucos bens; segunda, e em virtude da primeira, as mulheres objetivavam a imediata sobrevivência juntamente com a prole, por isso requeriam rápido pagamento da desejada pensão, mesmo que esta representasse "baixos" valores.

O que tais campos deixam ainda entrever, além das acusações das individualidades das partes? Contínuas ressignificações dos códigos que conduziam a investigação de paternidade, certamente era um significado, assim como alimentos, educação dos filhos e bens (pecúlios, propriedades, economias) sempre estiveram articulados como razões de processos. Poder-se-ia evocar a representação de que se pleiteavam valores econômicos e sociais que da convivência pregressa emanava; nos autos, esta dimensão valorizava-se e no decorrer do tempo processual ela crescia em seu interior. É impossível medir com precisão a amplitude dos fenômenos existentes no bojo desses documentos, contudo eles indicam a estas argumentações, pois que se considerava a família domínio muito sério porquanto esforços, ordens, tolerâncias e planos foram traçados em comum. Do patrimônio cultural e de bens de outros tempos, pensados e constituídos como ideais, sobravam agora tão somente alguns resquícios que se inseriam em contextos que lhes eram estranhos, como os da justiça.

Inúmeras são as possibilidades para se compreender as fortes tensões que se constrói ao longo da vida, então, tomar emprestada a tese de Maurice Aymard é coerente. Considera o historiador que os diversos grupos e personagens sociais para sobreviverem no interior das lutas e intrigas surgidas é de suma importância saber jogar bem o jogo dos contatos políticos, sociais e culturais "por si e pelos seus". (AYMARD, 1991, p. 455-499). Em conformidade com isso, as mulheres que entravam - na cidade de Belém - com processos de investigação de paternidade discutiam planos delicados e sensíveis que envolviam a base da sociedade, a família. Por isso mostravam possuir salutares prudências e, ao mesmo tempo, construíam de modo preciso argumentos e articulações.

Outro caso que ajuda a compreender tensões da vida é o de Maria Reis e Dilermando Martins de Oliveira Mello. A mulher era solteira, 21 anos, doméstica, miserável 
no sentido da lei, amparada pela Assistência Judiciária, residente na Avenida Tito Franco, 1644 e Dilermando Martins de Oliveira Mello, 28 anos, paraense, casado, funcionário público da Diretoria Geral de Agricultura e Pecuária do Pará, onde tinha como função a atividade de Auxiliar de Culturas, morador da Travessa Timbó, 1110. (Auto Civil de Investigação de Paternidade Cumulado com Prestação de Alimentos, 1940). Em março de 1939 teria ocorrido o possível defloramento, nascendo Norma Reis. Por seu turno, Dilermando e o seu advogado, Clovis da Gama Malcher, passaram a contestar o desvirginamento e consequente paternidade; o réu afiançava que nunca mantivera elos de namoro e nem tampouco sexuais com Maria, sendo inteiramente falsa a acusação de ser o genitor da menor em questão e que "em tempo algum, em qualquer lugar, na presença de quem quer que seja, nunca o réo, por palavras, atos ou qualquer outra manifestação de vontade, tacita ou expressamente, reconheceu a paternidade que se lhe quer atribuir". (Auto Civil de Investigação de Paternidade Cumulado com Prestação de Alimentos, 1940).

O cotidiano dialogava com a lei e isto justificava a cautela que se deveria ter diante do imaginável filho. Gestos, palavras e atos que pudessem sugerir proximidades sentimentais, apreço, carinho com a criança, mesmo se realizados em domínios particulares, precisariam ser negados diante do judiciário paraense, caso contrário o pagamento de provisões ficaria bem mais próximo. Tais ações constituíam-se campo difícil e dever-se-ia ter precauções, então, foi neste sentido de ressabiamento que o réu e seu advogado afirmavam que em tempo algum e em nenhum lugar [o acusado] se dirigiu com atos carinhosos à criança de que a "mãe dizia ser ele o pai". Para a segunda metade do século XX, entretanto na França, Gérard Vincent analisou o quanto as separações entre amásios eram sofridas e clivadas de tensões. Conforme o autor é absolutamente enganoso considerar que elas se organizavam em campos de menor complexidade ao tempo da vivência sob o mesmo teto ou quando da desunião dos amantes. Filhos, parentes, amigos, bens faziam-se presentes nas lutas da separação entre eles (amásios). (VINCENT, 1995b, p. 249-305).

Dilermando, atento aos perigos e penalidades contidos tanto no judiciário quanto em âmbito familiar - comprovou-se ser ele casado -, buscou cercar-se de possíveis provas de suas faculdades morais, isto é, de que não havia desvirginado a autora do processo e muito menos se constituía em pai de Norma Reis. De tal sorte, o impetrado conseguiu documento na Diretoria Geral de Agricultura e Pecuária do Pará, onde trabalhava, que asseverava que “durante os meses de Dezembro de 1938 á Junho de 1939” [em março de 1939 a autora afirmava ter sido deflorada] encontrava-se a serviço para o interior do Estado do Pará. Assim sendo era premente questionar tal assertiva, porque, as testemunhas de acusação passaram a 
dar as suas versões dos fatos: Manoel Soares de Souza, 51 anos, cearense, operário, casado, morador da casa número 21 da Estrada do Utinga, declarava que "via muito o réu Dilermando, conversando de noite e de dia com a mesma Maria Reis, dentro da casa da própria autora". Já, Florisbela Silva, 19 anos, paraense, solteira, doméstica, residente na casa número 1632 da Avenida Tito Franco, narrava que o contestador "apresentou Maria Reis á depoente, como sua futura noiva"; mais à frente a depoente expunha sempre ver "o réu e Maria passearem juntos" e Francisca Monteiro de Queiroz, 19 anos, casada, paraense, doméstica, residente na Estrada do Utinga, s/n que, ao ser interrogada, dava a versão de que "via sempre o réu e Maria Reis juntos, não vendo outro homem em sua companhia", um pouco mais adiante afirmava que tinha "certesa que no mez de abril de mil novecentos e trinta nove o réu estava aqui na cidade, porque o viu na casa de Maria Reis, assim no mez de janeiro tambem viu o acusado em companhia de Maria”. (Auto Civil de Investigação de Paternidade Cumulado com Prestação de Alimentos, 1940).

Em 13 de março de 1940, as imputações davam algum resultado, ou seja, Mauricio Cordovil Pinto concedia a palavra ao senhor doutor Miguel Machado da Rocha e Souza, Curador Geral; este opinava "pela condenação do réu por julgar que as provas contidas nos autos, são todas em favor da autora" e complementava:

a certidão que o réu juntou aos autos nenhum valor tinha uma vez que as testemunhas da autora são acordes em afirmar que o réu se encontrava nesta capital de Dezembro de mil novecentos e trinta e nove á Junho de mil novecentos e quarenta. (Auto Civil de Investigação de Paternidade Cumulado com Prestação de Alimentos, 1940).

Questionava-se a principal argumentação do acusado. Ela também se enfraqueceu, em 20 de março de 1940, quando o juiz certificava ser comum funcionários retirarem-se furtivamente - "e até de má fé" - das sedes de suas atividades. Caminhava-se pois para se comprovar ser Norma filha de Dilermando e se, por um lado esta criança ficava impossibilitada de reconhecimento visto que era adulterina diante da lei; por outro auferia-se o direito de receber pensão alimentícia, conforme os dispositivos do artigo 405 do Código Civil:

o casamento, embora nullo, e a filiação espúria, provada por sentença irrecorrigivel, não provocada pelo filho, quer por confissão, ou declaração escripta do pae, fazem certa a paternidade sómente para o effeito da prestação de alimentos. (Código Civil, 1917). 
Tomando por base o Código Civil, o juiz Cordovil julgou procedente o pagamento de provisões mensais de cinquenta mil réis, visto que considerava serem poucos os seus vencimentos, na ordem de duzentos e cinquenta mil réis, e também pelo seu estado de casado. Recorreu-se da condenação, mas não se obteve sucesso. Com efeito, a "amasiada", a "concubinada", a "amante" era vislumbrada com reticências de alguma e de todas as formas, todavia estas personagens quando entravam na justiça e a peleja se concentrava em pensão alimentícia, a visão do poder instituído mudava sensivelmente visto que o assunto enveredava a interessados maiores (os filhos) que mesmo ditos ilegítimos deveriam ser amparados pelos pais, segundo compreensão da lei.

A ordem jurídica [por meio da edificação de discursos de testemunhas, Assistentes Judiciários, Curadores Gerais e Advogados] fabricava culpados e inocentes. É imperativo, então, expor as interpretações de Celeste Zenha. Para a pesquisadora, a justiça produz em seu cotidiano o crime, assim como o criminoso (ZENHA, 1985, p. 123-146), e desta maneira, as reflexões realizadas convergiram às considerações da autora, visto que o exercício de poder realizado no judiciário da cidade de Belém do início do século XX interpretou-se como constante construção de imagens de "verdades" no bojo dos processos analisados.

Aos estudos realizados, muitas dinâmicas estavam presentes, todavia se destaca a da busca da sobrevivência. Estas foram as intenções das Marias, Antonias, Luizas, Izauras, Alziras, Ladis, mulheres que compuseram estes Cotidianos de Histórias.

\section{Considerações finais}

Quis-se nestes breves argumentos expor a ideia de que mulheres e filhos no seio de um processo de investigação de paternidade buscavam envolver necessariamente o cotidiano com as instâncias do poder jurídico, porquanto exigia-se que a vida pregressa viesse à tona, pois assim haveria mais chances de uma mulher, por exemplo, vencer a causa. $\mathrm{O}$ dia a dia era representado com falas de testemunhas que ajudariam a lembrar com mais detalhes as fases, dias, fatos e casos importantes, permanências e rupturas do casal, ou mesmo forjá-los. Vizinhos, amigos e parentes que pudessem apresentar pormenores e murmúrios da época do viver sob o mesmo teto, apresentavam-se importantes. Aqui mais uma vez torna-se importante recorrer a Nicole Castan, porque considerou a vizinhança instrumento de poder no sentido de saber como e em quais momentos ela conseguia viver a vida dos seus iguais. Em outras palavras, ela estabelecia nos interstícios do cotidiano diálogos e vigilâncias os quais "sempre" 
tiveram como propósito a solidariedade, a reciprocidade, mas também o controle dos seus pares. (CASTAN, 1991, p. 413-453).

É necessário afirmar que estas tramas não se recolheram do Código Civil de 1916 ou de qualquer jurista de época, conseguiram-se, sim, por meio dos diversos processos de investigação de paternidade estudados. Seja como for, provar por meio das testemunhas que os amantes viviam de "porta adentro" ao tempo da concepção, isto é, que conviviam juntos de forma a não deixar dúvidas aos julgadores, corroborava aos desejos de vitória.

A se dar crédito aoexposto, o "concubinado", o "amasiado", o "amancebado", o "em constante pecado", como queiram taxar os que conviviam às "margens" e sem necessidade da "ordem" do casamento dito legal, um fator comum se apresenta inerente a estas convivências: viver maritalmente não deve ser apreendido simplesmente como sexo furtivo, episódico ou fornicação, pois esta união foi detentora de felicidade, amor, paixão e durabilidade, assim como frustrações, dores e brigas diante, por exemplo, da divisão dos bens e prestação de alimentos.

Por tudo que se tratou, o que se nota não é uma mesma tentativa de "prova" em si, mas como ela foi movimentada em suas particularidades; grosso modo, a qualidade e o ritmo que cada acusação assumia, expressava diferença e força no forjar indulto ou culpa.Finalmente, quando se estudam as condições das práticas jurídicas, as ações que as mulheres nelas estabeleciam, assim como os espaços de condenação e absolvição, partir das diversidades e tempo que as mulheres - amásias, namoradas, concubinas, testemunhas enfrentavam, deve-se imediatamente considerar que este domínio representou fator decisivo no desenrolar do auto e na formatação de jurisprudência.

\section{Documentos}

A Palavra. Belém, 09 de setembro de 1923, p. 01.

Auto Civil de Investigação de Paternidade Impetrado por Maria Jacyntha Felix contra Vicente Pereira Leal, 1921.

Auto Civil de Investigação de Paternidade Impetrado por Antonia Pereira Lima contra os herdeiros de João Bussons, 1931.

Auto Civil de Investigação de Paternidade impetrado por Antonio da Silva Borges e outros contra Preciosa Rodrigues Borges, 1931.

Auto Civil de Investigação de Paternidade Cumulado com o de Herança impetrado por Luiza Ramos do Nascimento contra os herdeiros de Manoel Ramos do Nascimento, 1931. 
Auto Civil de Investigação de Paternidade Cumulado com Prestação de Alimentos impetrado por Izaura Gomes de Lima contra Carlos Flaviano Nascimento, 1940.

Auto Civil de Investigação de Paternidade e Petição de Herança impetrado por Alzira Gonçalves Galeão contra os herdeiros de Demetrio Moreira Pereira Lima, 1940.

Auto Civil de Investigação de Paternidade impetrado por Ladi Silva contra os herdeiros de José Marques dos Santos, 1940.

Auto Civil de Investigação de Paternidade e Petição de Herança impetrado por Alzira Gonçalves Galeão contra os herdeiros de Demetrio Moreira Pereira Lima, 1940.

Auto Civil de Investigação de Paternidade Cumulado com Prestação de Alimentos impetrado por Maria Reis contra Dilermando Martins de Oliveira Mello, 1940.

BEVILAQUA, Clovis. Código Civil dos Estados Unidos do Brasil. Vol. II. São Paulo: Livraria Francisco Alves, 1952.

Código Civil dos Estados Unidos do Brasil. Vol. II. Rio de Janeiro: Imprensa Nacional, 1917.

Folha do Norte. Belém, 01 de novembro de 1940, p. 02.

SÁ, Paulo. Divórcio ou casamento indissolúvel? Rio de Janeiro: S / Edição, 1946.

\section{Referências bibliográficas}

AYMARD, Maurice. "A comunidade, o Estado e a família. Trajetórias e tensões: amizade e convivialidade". In: ARIÈS, Philippe \& CHARTIER, Roger. (Orgs.). História da vida privada: da Renascença ao Século das Luzes. Vol. III. São Paulo: Companhia das Letras, 1991, p. 455-499.

CAMPOS, Ipojucan Dias. Casamento, custos e religiosidades: Belém, século XX (19161940). Revista Fronteiras, Campo Grande, v.12, n. 21, p. 179-201, jan/jun, 2010.

CASTAN, Nicole. O público e o particular. In: ARIÈS, Philippe \& CHARTIER, Roger. (Orgs.). História da vida privada: da Renascença ao Século das Luzes. Vol. III. São Paulo: Companhia das Letras, 1991, p. 413-453.

CAULFIELD, Sueann. Em defesa da honra: moralidade, modernidade e nação no Rio de Janeiro (1918-1940). São Paulo: Editora da UNICAMP, 2000.

DIAS, Maria Odila Leite da Silva. Teoria e método dos estudos feministas: perspectiva histórica e hermenêutica do cotidiano. In: COSTA, Albertina de Oliveira \& BRUSCHINI, Cristina. (Orgs.). Uma questão de gênero. Rio de Janeiro: Rosa dos Tempos, 1992, p. 39-53.

FOUCAULT, Michel. A verdade e as formas jurídicas. Rio de Janeiro: NAU, 2003.

MARTIN-FUGIER, Anne. Os atores: os ritos da vida privada burguesa. In: PERROT, Michelle. (Org.). História da vida privada: da Revolução Francesa à Primeira Guerra. Vol. IV. São Paulo: Companhia das Letras, 1999, p. 193-261. 
PERROT, Michelle. (Org.). Os atores: figuras e papéis. In: História da vida privada: da Revolução Francesa à Primeira Guerra. Vol. IV. São Paulo: Companhia das Letras, 2001, p. 121-192.

SENNETT, Richard. O declínio do homem público: as tiranias da intimidade. São Paulo: Companhia das Letras, 2002.

SILVA, Carmen da. O homem e a mulher no mundo moderno. Rio de Janeiro: Editora Civilização Brasileira, 1968.

VAITSMAN, Jeni. Flexíveis e plurais: identidades, casamento e família em circunstâncias pós-modernas. Rio de Janeiro: Rocco, 1994.

VINCENT, Gérard. As diversidades culturais. Os católicos: o imaginário e o pecado. In: PROST, Antoine \& VINCENT, Gérard. História da vida privada: da Primeira Guerra aos nossos dias. Vol. V. São Paulo: Companhia das Letras, 1995a, p. 393-425.

Uma história do segredo: segredos de família. In: PROST, Antoine \& VINCENT, Gérard. História da vida privada: da Primeira Guerra aos nossos dias. Vol. V. São Paulo: Companhia das Letras, 1995b, p. 249-305.

ZENHA, Celeste. As práticas da justiça no cotidiano da pobreza. Revista Brasileira de História, Rio de Janeiro, v. 05, n. 10, p. 123-146, mar/ago, 1985.

ARTIGO ENVIADO EM: 20/02/2017

ARTIGO ACEITO PARA PUBLICAÇÃO EM: 03/06/2017 